Wayne State University

DigitalCommons@WayneState

Nursing Faculty Research Publications

Nursing

$1-1-2003$

\title{
Functional Health Literacy in an Urban Primary Care Clinic
}

\author{
Nancy Trygar Artinian \\ Wayne State University, nancy.marie.artinian@wayne.edu \\ M. Patricia Lange \\ John D. Dingell Veterans Medical Center \\ Thomas Templin \\ Wayne State University \\ Lynda G Stallwood \\ Wayne State University \\ Christopher E. Hermann \\ John D. Dingell Veterans Medical Center
}

\section{Recommended Citation}

Artinian, N. T., Lange, M. P., Templin, T. N., Stallwood, L. G., \& Hermann, C. E. (2003). Functional Health Literacy in an Urban Primary Care Clinic. The Internet Journal of Advanced Nursing Practice, 5(3). doi:10.5580/deb

Available at: http://digitalcommons.wayne.edu/nursingfrp/1

This Article is brought to you for free and open access by the Nursing at DigitalCommons@WayneState. It has been accepted for inclusion in Nursing Faculty Research Publications by an authorized administrator of DigitalCommons@WayneState. 


\title{
Functional Health Literacy in An Urban Primary Care Clinic
}

NANCY T. ARTINIAN $P h D, R N, F A H A$, Associate Professor ${ }^{1}$; M. PATRICIA LANGE $P h D, A P R N, B C$, Associate Chief of Nursing Education and Research ${ }^{2}$; THOMAS N. TEMPLIN PhD, Associate Professor of Research ${ }^{1}$; LYNDA G. STALLWOOD $R N, B S N, M S N$, Doctoral Student ${ }^{1}$; CHRISTOPHER E. HERMANN $R N, B A, M S N, N P-C$, Graduate Student at the time the work was completed, Pulmonary Medicine ${ }^{2}$

\begin{abstract}
The purpose of this study was to determine the level of functional health literacy in a sample of patients treated in 1of our 5 primary care clinics. A total of 92 randomly selected adults (mean age $=59$ years) completed the TOFHLA while waiting for a scheduled appointment. Twenty eight percent of the sample had less than adequate levels of functional health literacy. Income, car ownership and education were significant and independent predictors of literacy level in this sample. Low levels of functional health literacy limit a patient's ability to read, understand and act on health information. It is essential that nurse practitioners and clinical nurse specialists use relevant cues to assess for illiteracy and modify their methods of providing health information when appropriate.
\end{abstract}

${ }^{1}$ College of Nursing, Wayne State University

${ }^{2}$ John D. Dingell Veterans Medical Center

Citation: Artinian, N. T., Lange, M. P., Templin, T. N., Stallwood, L. G., \& Hermann, C. E. (2003). Functional Health Literacy in an Urban Primary Care Clinic. The Internet Journal of Advanced Nursing Practice, 5(3). doi:10.5580/deb

\section{WAYNE STATE UNIVERSITY COLLECE OF NURSING}

\section{Introduction}

Health illiteracy is a problem that often goes unrecognized by health care providers despite the fact it affects millions of Americans and costs the health care system an estimated $\$ 73$ billion annually [ $\left.{ }^{1}\right]$. According to the National Adult Literacy Survey (NALS) $\left[{ }^{2}\right]$, the largest household-based literacy assessment every conducted in the United States (U.S.), approximately 40 to 44 million persons in the U.S. have literacy competency skills at the lowest level (level 1 of 5) of prose, document and quantitative 
proficiencies. This means they can read a little, but not well enough to fill out an application, read a food label, or read a simple story to a child. Between 45 and 50 million adults nationwide have literacy skills in the next higher level of proficiency (level 2 of 5), which means their skills are still quite limited, but are generally able to locate information in text, to make low-level inferences using printed materials, and to integrate easily identifiable information. They can perform quantitative tasks if they only involve a single operation where the numbers are either stated or can easily be found in text $\left[{ }^{2},{ }^{3}\right]$. Individuals in levels 1 and 2 cannot manage challenging literacy tasks such as synthesizing information from complex or lengthy texts, or performing quantitative tasks that involve two or more sequential operations, and in which the individual had to set up the problem.

Health literacy is the ability to read, understand and act on written material commonly encountered in health care settings $\left[{ }^{4}\right]$. Functional health literacy is the ability to apply reading and numeracy skills in a health care setting $\left[^{5}\right]$. Parker and colleagues $\left[{ }^{6}\right]$ describe functional health literacy as having two components, i.e., reading comprehension and numeracy. Reading comprehension refers to the ability to read and understand written word passages of health-related information. Numeracy refers to the ability to read and understand numbers. With low levels of functional health literacy, an individual cannot understand consent forms, medicine labels and inserts, and other written health care information.

An inability to understand impairs an individual's ability to act upon necessary procedures and directions, such as medication and appointment schedules; it also affects a nurse practitioner's approach to providing written and oral information. In a sample of 50 patients with hypertension (mean age $=60.3$ years), receiving care in a neighborhood health center, French and Larabee $\left[^{7}\right]$ demonstrated that patients' mean measured reading grade level $(\mathrm{M}=6.57)$ was significantly lower than both their mean years of education $(\mathrm{M}=9.3)$ and the 12th grade readability level of the educational pamphlet about hypertension used at the health center.

Adults with chronic medical problems face tremendous learning demands. Their ability to learn to self-management of the demands of chronic illness partially determines whether or not they will experience illness stability or years of struggling with the exacerbations and disability of illness. In a sample of adults (mean age 54 years) diagnosed with diabetes for an average duration of 6 years, Slocum et al. $\left.{ }^{8}\right]$ found that higher literacy scores were associated with lower HbA1c levels on initial visit to the diabetes clinic. Gordon et al. $\left[{ }^{9}\right]$ examined the impact of illiteracy on disease severity and function in a sample of 123 patients (median age 56 years) with rheumatoid arthritis. Although sex, age, disease duration, and numbers of joint replacements were not influenced by illiteracy, illiterate patients had more anxiety and had three times more hospital visits when compared to the patients with higher literacy scores. Other investigators have examined the relationship between health literacy and a 2-day recall of HIV and AIDS treatment adherence and found that education and health literacy were significant and independent predictors of treatment adherence $\left[{ }^{10}\right]$.

Use of preventive services also is influenced by health literacy. Scott et al. $\left[{ }^{11}\right]$ found that inadequate health literacy is independently associated with lower use of preventive services such as receiving influenza and pneumococcal vaccinations, mammograms, and Papanicolaou smears. Other investigators found health literacy to be associated with advanced prostate cancer at diagnosis, $\left[{ }^{12}\right]$ possibly due to inadequate use of prevention cancer screening services such as receiving prostate-specific antigen tests. 
Several investigators have described demographic characteristics associated with lower health literacy. The NALS found that adults who were older, had relatively few years of education, or who were in prison, were more likely to have limited literacy skills. Black, American Indian/Alaskan Native, Hispanic, and Asian/Pacific Islander adults were more likely than White adults to perform in the two lowest literacy levels. Additionally, the NALS found the functionally illiterate were more likely to be poor, unemployed, and working in jobs subject to seasonal and general economic fluctuations [2]. Sum et al. [ $\left.{ }^{13}\right]$ reported the average literacy score of native-born adults in the U.S. is level 3; the average literacy score of foreign-born adults in the U. S. is level 1.

Benson and Forman $\left[{ }^{14}\right]$ administered the Test of Functional Health Literacy to 93 residents (mean age 83 years, average of 15 years education) of a retirement apartment community. Multivariate analysis demonstrated a statistically negative effect of age on the literacy score $(\mathrm{p}=.04)$, and a statistically positive effect of years of education on the literacy score $(\mathrm{p}=.0005)$, but no statistically significant effect of gender on the score $(\mathrm{p}=$ .20). Gazmararian et al. $\left.{ }^{[15}\right]$ tested the reading ability and health literacy of 3,260 Medicare beneficiaries 65 years of age or more. Thirty-four percent of the English speaking and 54\% of the Spanish-speaking patients had inadequate or marginal health literacy. African American, older age, poor education, and blue-collar occupation were associated with poor health literacy.

Knowing the prevalence of illiteracy in the U.S., this study attempted to better understand the level of literacy among the adult patients within our urban primary care clinics. In order for individuals to regularly participate in prevention and health maintenance activities, and to successfully self-manage their chronic illnesses, there is a need to provide health care information that will be understood and appropriate to their functional health literacy skills. Therefore, the purpose of this study was to determine the level of functional health literacy in a sample of patients treated in 1 of our 5 primary care clinics. This study addressed the following research questions:

1. What is the level of ability to read passages of health care information commonly provided in a primary care clinic?

2. What is the level of ability to read and understand numbers as commonly seen on medication prescriptions?

3. What characteristics differentiate patients with adequate, marginal and inadequate literacy levels?

\section{Methods}

Design, Setting and Sample. This non-experimental descriptive study was conducted in a Midwestern Veterans' Administration Medical Center (VAMC) that has 5 primary care outpatient clinics organized according to medical specialty. Approximately 40 patients are seen daily in each clinic. Patients wait on average 30 to 60 minutes for their scheduled clinic appointments. 
Using clinic appointment lists as the sampling frame, participants were randomly selected using their patient identification number. Patients were selected if they met the following criteria: age 18 years of age or older, understood English, scheduled patient in one of the primary care clinics, and consented to participate.

Data Collection. Data were collected while patients were waiting for their scheduled appointment. Following an explanation of the study and written consent, all participants completed a demographic questionnaire and the Test of Functional Health Literacy of Adults (TOFHLA). Participants completed their questionnaires in a private exam room, with completion of questionnaires taking approximately 30 minutes. Approximately 30$40 \%$ of those approached regarding the study refused to participate. Patients who refused to participate may have done so out of embarrassment associated with discussing reading ability.

Instruments. An investigator-developed demographic questionnaire was used to collect information about age, gender, race, and socioeconomic status. The TOFHLA was used to assess functional health literacy in the sample [6]. The test is composed of 2 parts: Reading Comprehension and Numeracy. The Reading Comprehension section is a 50-item test using the modified Cloze procedure, i.e., every 5th to 7 th word in a passage is omitted. The reader selects from four possible choices, one of which is correct and the others, which are similar but either grammatically or contextually incorrect. Passages were selected from instructions for preparation for an upper gastrointestinal series, the patient rights and responsibilities of a Medicaid application form, and a standard hospital informed consent form. The readability levels of the passages on the Fog Index are grades $4.3,10.4$, and 19.5 respectively. The total possible reading comprehension score range is 0 to 50 .

The numeracy section is a 17-item test using actual hospital forms and labeled prescription vials. It tests a patient's ability to comprehend directions for taking medicines, monitoring blood glucose, keeping clinic appointments, and obtaining financial assistance. Patients are provided with cue cards and asked to respond to oral questions regarding information on the cards. The overall readability level of the Numeracy prompts on the Fog index is 9.4. The Numeracy score is multiplied by 2.911 to create a score from 0 to 50 . The total TOFHLA score is the sum of the Reading Comprehension and weighted Numeracy scores, which ranges from 0 to 100 [6].

Reliability and validity of the TOFHLA are reported as follows. In a sample of 256 English-speaking outpatients from 2 public teaching hospitals, the Cronbach's alpha reliability was found to be .98 . In the same sample, convergent validity was established by correlating the TOFHLA with the WRAT-R $(r=.74, \mathrm{p}<.001)$ and Rapid Estimate of Adult Literacy in Medicine (REALM) $(\mathrm{r}=.84, \mathrm{p}<.001)$, two other widely used literacy level assessments [6].

Data Analysis. Data analysis procedures were conducted using SPSS-PC. Descriptive statistics were used to analyze all study variables and the first 2 research questions. Chisquare, one-way analysis of variance (ANOVA), and forward regression analyses were used to answer the third research question. The significance level was set at .05. 


\section{Results}

Sample Characteristics. A total of 92 patients, $89(96.7 \%)$ males and 3 females $(3.3 \%)$ were included in the sample. Participants' ages ranged from 23 to 92 years with a mean of 59 years. The sample contained 45 white-Americans $(49 \%)$ and $42(46 \%)$ African Americans; five (5\%) were Hispanic or from another racial group. Participants' years of education ranged from 2 to 18 with a mean of 12 years. Sixty-one percent $(\mathrm{n}=$ $56)$ of the sample was single, widowed, divorced or separated and $39 \%(\mathrm{n}=36)$ was married.

The majority $(n=62,67 \%)$ of the sample was unemployed, $29(32 \%)$ did not own a car, $12(13 \%)$ reported not having a telephone in their home, and $6(6.5 \%)$ reported receiving financial assistance to buy food. Seventy percent $(n=57)$ of the sample had annual household incomes less than $\$ 30,000$ (Note: 10 participants did not provide income data).

Levels of Functional Health Literacy in the Sample. Scores on the TOFHLA have a possible range from 0 to 100 . TOFHLA scores of 0 to 59 reflect inadequate levels of functional health literacy, scores 60 to 74 reflect marginal levels, and scores 75 to 100 reflect adequate levels. Figure 1 describes the proportions of inadequate, marginal and adequate functional health literacy in this sample. The mean functional health literacy score in the sample was 78, which means the majority of patients in this sample barely had adequate levels of literacy. Twenty eight percent of the sample had less than adequate levels of functional health literacy.

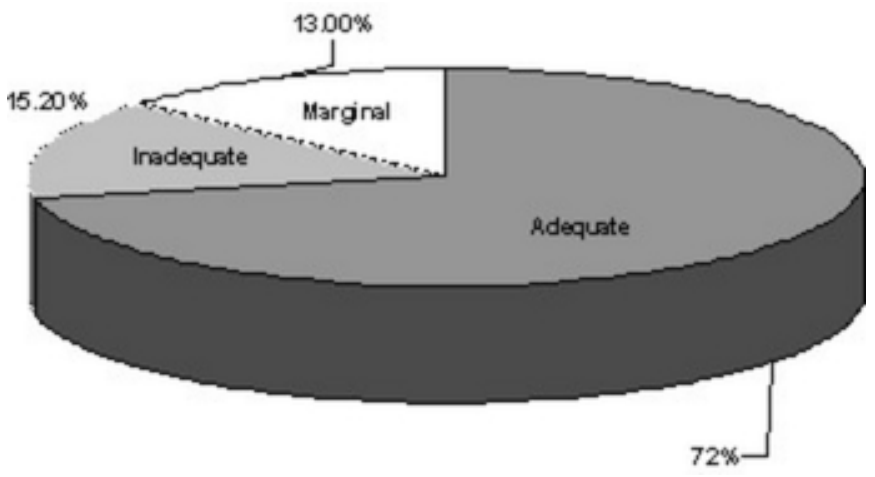

Figure 1: Levels of Functional Health Literacy in the Sample

Reading comprehension and numeracy contributed equally to the total functional health literacy score. Mean scores for reading comprehension and numeracy were 39 (out of a possible of 50). Patients were able to read and understand passages of health information as well as read and understand materials that contained numbers with equal levels of ability.

Characteristics Associated with Adequate, Marginal and Inadequate Levels of Literacy. Several analyses were used to determine if the levels of inadequate, marginal and adequate functional health literacy differed by the following demographic characteristics: age, race, years of education, marital status, income, employment status, or car ownership status. Patients who had less than adequate levels of functional health 
literacy were older in age ( $\mathrm{M}=69$ years $)$, had significantly fewer years of education $(\mathrm{M}=$ 10.50 years), and had significantly lower annual household incomes $(M=\$ 10,300)$ than patients with adequate levels of literacy (means for age, education, and income were respectively, $\mathrm{M}=56$ years, $\mathrm{M}=12.47$ years, $\mathrm{M}=\$ 20,000)$. A one-way ANOVA determined that these differences were significant at less than the .001 level.

Frequencies for race, marital status, employment, and car ownership status were compared across the literacy level groups. Significantly more $(\mathrm{p}=.046)$ white Americans $(n=36,80 \%)$ had adequate levels of literacy than African Americans $(n=28,67 \%)$. Significantly more $(\mathrm{p}=.041)$ patients who were married or who were able to identify a partner $(n=31,86 \%)$ had adequate levels of literacy than patients who were single or without a partner $(n=35,62.5 \%)$. Significantly more $(\mathrm{p}=.009)$ patients who were employed $(n=27,90 \%)$ had adequate levels of literacy than veterans who were not employed $(\mathrm{n}=39,63 \%)$, and significantly more $(\mathrm{p}=.043)$ patients who owned are car $(\mathrm{n}$ $=50,79 \%)$ had adequate levels of literacy than patients who did not own a car $(\mathrm{n}=16$, $52 \%)$.

To attempt to account for the impact of race on literacy with greater precision, a forward selection regression analysis was performed. With this type of analysis, each variable in a defined set of potential predictors is added to the regression equation one at a time according to the following rules: a) compute the amount of variance each variable in the set accounts for in the outcome (functional health literacy) and then add to the prediction equation the one which accounts for the greatest amount of variance; and b) repeat this step with the remaining variables, adding variables until no variables remain in the set of potential predictors that account for a significant amount of additional variance. The set of potential predictors consisted of age, race, years of education, marital status, income, employment status, and car ownership. The significant predictors of functional health literacy were found to be income, car ownership, and education. The variables of age, race, marital status, and employment did not account for any significant amount of variance once income, car ownership, and education were in the equation. Table 1 shows that each of these variables made an independent and significant contribution to literacy level.

\begin{tabular}{|l|c|c|c|}
\hline \multicolumn{1}{|c|}{ Predictor Variables } & Beta (SE) & t-value & $\begin{array}{c}\text { p- } \\
\text { value }\end{array}$ \\
\hline $\begin{array}{l}\text { Literacy } \\
\quad \text { Income }\end{array}$ & 252 & 2.421 & .018 \\
$\quad \begin{array}{l}\text { Car Ownership } \\
\text { Education }\end{array}$ & -.225 & -2.204 & .030 \\
Age, Race, Marital Status and Employment & $\begin{array}{c}\text { Excluded } \\
\text { variables }\end{array}$ & 3.167 & .002 \\
& & \\
\hline
\end{tabular}

Table 1: Standardized Regression Coefficients, t, and R2 Values for Functional Health Literacy 


\section{Discussion and Implications for Practice}

As the findings of this study are interpreted, it is important to keep in mind that there was an estimated $30 \%$ to $40 \%$ refusal rate, which may have introduced sample bias. Those refusing may have done so out of embarrassment associated with discussing reading ability. The actual rate of inadequate literacy may have been considerably higher than measured. Despite this limitation, $28 \%$ of the patients in this sample had less than adequate levels of functional health literacy. This number is a sizable minority of the sample, and is significant when considered within the context of approximately 26,000 outpatient visits in the primary clinics each year. Less than adequate health literacy means these patients have difficulty reading a prescription label, a thermometer, a consent form, a health information pamphlet, signage providing directions around the medical center, or even a bus schedule to get to the outpatient clinic for their appointment.

Knowing that a certain level of inadequate health literacy exists, makes the ability to recognize illiteracy an important one. According to the Joint Commission on Accreditation of Healthcare Organizations' (JCAHO) standards on patient and family health education [16], it is incumbent upon health professionals to identify learning and educational needs, use appropriate educational resources, and to assess the patient's and family's ability to comprehend, use and apply information taught. Assessment of literacy level is an essential part of this process. However, amid the demands of disease management, understanding complex clinical presentations, knowing multiple differential diagnoses, interpreting laboratory and diagnostic tests, literacy assessment may pale in comparison. Moreover, it may be easy to lose sight of patients' unique concerns, especially as related to literacy, when care is often carried out in health care settings increasingly fraught with time demands and cost concerns.

Keeping the benefits of literacy assessment in mind may motivate nurse practitioners and clinical nurse specialists to find ways to address the issue of delivering care suitable to a patient's literacy level. Delivering care tailored to patients' literacy levels is key to enabling patients to engage in the process of care and to accessing all the resources that may be available to them. Literacy assessment is an important component of effective advanced practice nurse-patient communication, enabling a nurse practitioner or clinical nurse specialist to elicit a better medical history, explain a treatment plan in understandable terms, assist the patient to integrate treatment recommendations into their usual daily routine, be sensitive to other psychosocial issues the patient may be dealing with, and convey empathy. All of these factors may lead to increased patient satisfaction with care, an important health care outcome and indicator of quality of care that is valued by patients, payors, and health care administrators.

A wide variety of formal and informal methods of screening for reading and comprehension in English and Spanish, including REALM, WRAT-3, SORT-R, TOFHLA (as used in this study), and others have been described in the literature [17]. Table 2 provides brief information about these tests. It may be worthwhile including a literacy test in the packet of "new patient" assessment materials and routinely screening all patients. 
FUNCTIONAL HEALTH LITERACY / ARTINIAN ET AL.

\begin{tabular}{|c|c|c|}
\hline Test & Description & Order Information \\
\hline $\begin{array}{l}\text { SORT-R(Slosson } \\
\text { Oral Reading Test. } \\
\text { Revised) }\end{array}$ & 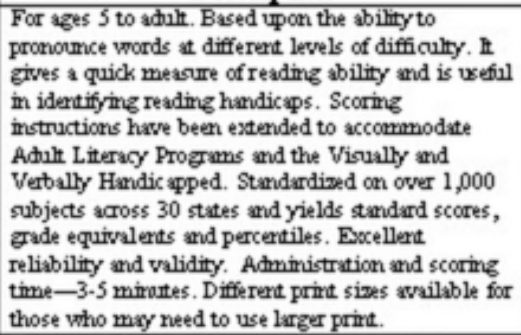 & $\begin{array}{l}\text { Slosson Educational Publications, } \\
\text { Inc., } \\
\text { P.. O. Box } 280 \\
\text { East Aurora } \\
\text { FY } 14052-0280 \\
1-800-221-9728 \\
\text { huld:/Awww.slossoncom } \\
\text { There is a charge to order the SORT. } \\
\text { R. The fee covers a marual, tests } \\
\text { and score sheets. }\end{array}$ \\
\hline $\begin{array}{l}\text { WRAT-3 } \\
\text { (Wide Range } \\
\text { Achievement Test) }\end{array}$ & $\begin{array}{l}\text { For ages } 5 \text { through } 75 \text { years. } 3 \text { componerts: } \\
\text { reading, spelling and arithmetic. The whole test } \\
\text { takes } 15-30 \text { mirutes to administer. The reading } \\
\text { componert can be administered alone, takes about } 5 \\
\text { miruites, and is a word recogution test. Individuals } \\
\text { read aloud from a list of words of progressive } \\
\text { difficulty. The more words they can pronounce } \\
\text { correctly, the higher their reading skill Nationally } \\
\text { standardized test, nommed by age not grade level to } \\
\text { compare an individual's performance with others of } \\
\text { the same age. }\end{array}$ & $\begin{array}{l}\text { Wide Range, hrc. } \\
\text { P.0. Box } 3410 \\
\text { Wilmington, DE } \\
19804-0250 \\
1-800-221-9728 \\
\text { help:/hwww widermge.com } \\
\text { There is a charge to order the } \\
\text { WRAT-3. The fee covers a marual, } \\
\text { tests and score sheets. }\end{array}$ \\
\hline $\begin{array}{l}\text { REALM } \\
\text { (Rapid Estimate of } \\
\text { Adult Literacy in } \\
\text { Medicine) }\end{array}$ & $\begin{array}{l}\text { Has only been validated with adults. Similar to the } \\
\text { WRAT test, however individual reads from a list of } \\
66 \text { health medical words. Words are arr anged in } 3 \\
\text { cobnms beginning with short and eary words. High } \\
\text { criterion validity, correlating with The WRAT-3 and } \\
\text { SORT-R Takes about } 5 \text { mirates to admirister. }\end{array}$ & 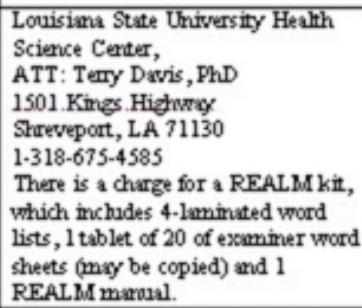 \\
\hline $\begin{array}{l}\text { TOFHLA } \\
\text { (Test of Fmational } \\
\text { Health Literacy in } \\
\text { Adults }\end{array}$ & $\begin{array}{l}\text { Measures reading comprehension and rommeracy, } \\
\text { (refer to article for more description.) Takes up to } 22 \\
\text { miruites to administer. Good criterion validity, } \\
\text { correlating with the reading section of the WRAT-3 } \\
\text { and with the REALM; good intemal reliability. } \\
\text { Available in English and Spanish; } 12 \text { and } 14 \text { poirt } \\
\text { fort versions avallable. }\end{array}$ & $\begin{array}{l}\text { Cortact Joarne R. Furss, PhD } \\
\text { Director, Certer for the Study of } \\
\text { Adult Literacy } \\
\text { Professor, Etucational Psychology } \\
\text { \& Special Etucation } \\
\text { University Plaza } \\
\text { Atlarta, GA } 30303-3083 \\
\text { 1-404-651-2405 }\end{array}$ \\
\hline
\end{tabular}

Table 2: Popular Literacy Tests

Asking patients about whether they can read will not help advanced practice nurses identify patients with low literacy. According to the NALS [2], 66 to $75 \%$ of the adults in the lowest literacy level and 93 to $97 \%$ in the second lowest level, described themselves as being able to read or write English "well" or "very well." If all patients making outpatient visits do not participate in some form of literacy assessment, looking for cues to identify patients at high risk for lower levels of functional health literacy is critical. In this study, less than adequate levels of literacy were associated with older age, African American race, unpartnered marital status, lower education, lower income, unemployment and not owning a car, but a regression analysis revealed only income, car ownership and education as significant and independent predictors. These predictors are simple cues that nurse practitioners or clinical specialists can use to identify at risk patients. Once high-risk patients are identified, further assessments to confirm the level of literacy are essential.

It is important for advanced practice nurses to be able to use a readability formula to find out if the documents they routinely use for providing health information are at the right reading level for their patients. Health information on the Internet should be among the sources of health information assessed. Wilson et al. [18] assessed patient-related 
cancer information through CancerNet, the Web site of the National Cancer Institute, and found the mean overall reading level was 12 th grade, a level that is too high to be useful to individuals with low reading skills.

The Fog Index is a popular and easy to use readability formula and is used to measure the reading difficulty of any document. The index is base on the premise that the bigger the words used ( 3 or more syllables), and the more complex the sentences (more words/sentence), the more difficult the document is to read. The Fog Index gives the number of years of education that your patient needs to understand the material they are reading [19]. Typing "Fog Index" into any Internet search engine will bring up multiple sites that provide directions for using the Fog Index. Other readability scores, Flesch Reading Ease Score and Flesch-Kincaid Grade Level score are available through using Microsoft Word ${ }^{\circledR}$ for Windows. To access the information available using Microsoft Word ${ }^{\circledR}$, use the following steps: 1) click on the help menu; 2) click on Microsoft Word help: 3) type in the words "readability test" then click search; 4) a menu with several options will appear, click "readability scores", the score calculations will appear.

Health education materials need be available to accommodate the sizable minority of primary care outpatients at high risk for functional health illiteracy. The U.S. Food and Drug Administration provides many easy-to-read health brochures in both English and Spanish. These brochures are available on their Website in both PDF and HTML formats (http://www.fda.gov/opacom/lowlit/7lowlit.html). Another good resource for health materials for use with limited-literacy adults is the Health and Literacy Compendium. World Education developed the Compendium in collaboration with the National Institute for Literacy to share literacy information and easy-to-read health materials with health professionals. The Web version of the Compendium, which will be regularly updated, is available at http://easternlincs.worlded.org. The Web version is searchable and includes direct links to resources cited.

\section{Conclusions}

In summary, a sizable minority of primary care outpatients have low levels of functional health literacy which limits their understanding of health information and potentially leads to poor health outcomes. It is essential that nurse practitioners or clinical specialists use relevant cues to assess for illiteracy and modify their methods of providing health information when appropriate.

Correspondence to: Nancy T. Artinian, PhD, RN, FAHA 732 Keaton Dr. Troy, MI 48098 (248)

879-9781 (w) (248) 879-9781 (fax) n.artinian@wayne.edu

\section{References}

1. Smoak RD: AMA Foundation to improve health literacy. Am Med News 2000; 43(13): 20.

2. Kirsch I., Jungeblut A, Jenkins L, Kolstad A: Executive summary of adult literacy in America: A first look at the results of the National Adult Literacy Survey; Washington, DC: National Center for Education Statistics, Office of Educational Research and Improvement, U.S. Department of Education. Retrieved July 15, 2002 from http://nces.ed.gov/naal/resources/execsumm.asp

3. National Institute for Literacy: Frequently asked questions. Washington, DC: National Institute for Literacy. Retrieved July 15, 2002 from http://nifl.gov 
4. Scott TL, Gazmararian JA, Williams MV, Baker DW: Health literacy and preventive health care use among medicare enrollees in a managed care organization. Med Care 2002: 40(5):395-404.

5. Center for Health Care Strategies: What is health literacy? Lawrenceville, NJ: Center for Health Care Strategies, Inc. Retrieved July 15, 2002 from http://www.chcs.org/resource/hl.html

6. Parker RM, Baker D W, Williams M V, Nurss J R: The test of functional health literacy in adults: A new instrument for measuring patients' literacy skills. Journal of Gen Intern Med 1995: 10:537-541.

7. French KS, Larrabee JH: Relationships among educational material readability, client literacy, perceived beneficence, and perceived quality. Journal of Nursing Care Quality 1999; 13(6):68-82.

8. Slocum W, Ryan G, Gallina DL, Ferguson S Y, Ernst K: Literacy assessment in an urban, municipal hospital diabetes clinic. Diabetes 1999; 48(5):SA 158.

9. Gordon M, Hampson R, Capell HA, Madhok R: Illiteracy in rheumatoid arthritis patients as determined by the Rapid Estimate of Adult Literacy in Medicine (REALM) score. Rheumatology 2002; 41(7):750-754.

10. Kalichman SC, Ramachandran B, Catz S: Adherence to combination antiretroviral therapies in HIV patients of low health literacy. Journal of General Internal Medicine 1999; 14(5):315317.

11. Scott $T$, Gazmararian JA, Williams MV, Baker DW: Health literacy and preventive health care use among medicare enrollees in a managed care organization. Med Care 2002; 40(5):395404.

12. Kim SP, Bennett CL, Chan C, Chmiel J, Falcone D, Knight SJ, Kuzel T, Davis T C, Elstein AS, Moran E, Robertson, CN, Smith JS: QOL and outcomes research in prostate cancer patients with low socioeconomic status. Oncology 1999; 13(6):823-832.

13. Sum A, Kirsch I, Taggart R: The twin challenges of mediocrity and inequality: Literacy in the U.S. from an international perspective. Princeton, NJ: Policy Information Center, Educational Testing Service, 2002;1-42.

14. Benson J, Forman WB: Comprehension of written health care information in an affluent geriatric retirement community: Use of the Test of Functional Health Literacy. Gerontology 2002; 48:93-97.

15. Gazmararian JA, Baker D W, Williams M V, Parker R M, Scott T L, Green D C, Fehrenbach N, Ren J, Koplan J P: Health literacy among medicare enrollees in a managed care organization. JAMA 1999; 281(6):545-551.

16. Joint Commission for Accreditation of Health Care Organizations: 2002 Hospital Accreditation Standards (pp.1-15). Oakbrook Terrace, IL: Joint Commission for Accreditation of Health Care Organizations, 2002.

17. Davis TC, MR, Askov EN, Williams MV, Weiss B D: Practical assessment of adult literacy in health care. Health Educ Behav 1998; 25(5):613-624.

18. Wilson FL, BL, Brown-Syed C, Gollop C: An analysis of the readability and cultural sensitivity of the information on the National Cancer Institute's Web Site: CancerNet. Oncology Nursing Forum 2000; 27(9):1403-1409.

19. Costello P, Fleck J, Kirillov A, O'Connor E, GNOME Documentation Style Guide. Retrieved July 18, 2002 from http://developer.gnome.org/documents/style-guide/index.html 